\title{
Patients with pelvic fractures due to falls: A paradigm that contributed to autopsy-based audit of trauma in Greece
}

\author{
Iordanis N Papadopoulos ${ }^{1 *}$, Nikolaos K Kanakaris ${ }^{1}$, Stefanos Bonovas², George Konstantoudakis ${ }^{1}$, \\ Konstantina Petropoulou', Spyridon Christodoulou', Olympia Kotsilianou', Christos Leukidis ${ }^{3}$
}

\begin{abstract}
Background: Evaluation of the pelvic fractures (PFx) population in auditing effective components of trauma care is the subject of this study.

Methods: A retrospective, case-control, autopsy-based study compared a population with PFx to a control-group using a template with trauma outcome variables, which included demographics, ICD-9, intention, mechanisms, toxicology, Abbreviated Injury Scale (AIS-90), Injury Severity Score (ISS), causes of haemorrhage, comorbidity, survival time, pre-hospital response, in hospital data, location of death, and preventable deaths.

Results: Of 970 consecutive patients with fatal falls, 209 (21.5\%) had PFx and constituted the PFx-group while 761 (78.5\%) formed the control-group.

Multivariate analysis showed that gender, age, intention, and height of fall were risk factors for PFx. A 300\% higher odds of a psychiatric history was found in the PFx-group compared to the control-group $(p<0.001)$.

The median ISS was 50 (17-75) for the PFx-group and 26 (1-75) for the control-group ( $p<0.0001)$. There were no patients with an ISS less than 16 in the PFx group.

Associated injuries were significantly more common in the PFx-group than in the control-group. Potentially preventable deaths (ISS < 75) constituted 78\% ( $n=163$ ) of the PFx-group. The most common AIS3-5 injuries in the potentially preventable subset of patients were the lower extremities in $133(81.6 \%)$, thorax in $130(79.7 \%)$, abdomen/pelvic contents in 99 (60.7\%), head in 95 (58.3\%) and the spine in 26 (15.9\%) patients. A subset of 126 (60.3\%) potentially preventable deaths in the PFx-group had at least one AIS-90 code other than the PFx, denoting major haemorrhage. Deaths directly attributed to PFx were limited to 6 (2.9\%). The median survival time was 30 minutes for the PFx-group and 20 hours for the control-group $(p<0.001)$. For a one-group increment in the ISS-groups, the survival rates over the post-traumatic time intervals were reduced by $57 \%(p<0.0001)$.

Pre-hospital mortality was significantly higher in the PFx-group i.e. $70.3 \%$ of the PFx-group versus $42.7 \%$ of the control-group ( $p<0.001)$.

Conclusions: The PFx-group shared common causative risk factors, high severity and multiplicity of injuries that define the PFx-group as a paradigm of injury for audit. This reduced sample of autopsies substantially contributed to the audit of functional, infrastructural, management and prevention issues requiring transformation to reduce mortality.
\end{abstract}

\footnotetext{
* Correspondence: ipapado@med.uoa.gr

${ }^{1}$ National \& Kapodistrian University of Athens, Attikon University General

Hospital, Fourth Surgery Department, 1 Rimini Street, 124 62, Athens, Greece

Full list of author information is available at the end of the article
} 


\section{Background}

An evidence based transformation of trauma care is nowadays necessary. Nationally based trauma databanks and prospective research have substantially contributed to this task. Autopsy based audit remains a useful option, but selecting the trauma population in order to audit trauma care is an essential issue.

Pelvic fractures (PFx) are recognized as severe injuries that leave 'a record' on the patients with respect to the direction and magnitude of the force of impact, which helps to predict the patterns of commonly associated organ injuries [1]. In a recent publication [2], PFx related fatalities were used as a basis to audit the trauma care system in Greece.

The rational and the theoretical basis of selecting PFx to audit trauma care is that the pelvis is an inherently stable structure, hence large energy absorption is required to produce a PFx. Energy dissipation causes many life threatening associated injuries. Hence, selecting the population with PFx should select a reproducible population, thus allowing data comparison.

The present study used PFx population due to falls as a paradigm of injury in order to define its contribution in auditing trauma care.

\section{Patients and Methods Objectives}

The primary objective of this study was to define the role of the PFx population due to falls in auditing effective components of the trauma care delivery system.

\section{Design}

This is a retrospective, case-control study based on autopsy findings.

\section{Settings}

To achieve the defined objectives the course from injury to death of all consecutive casualties who suffered fatal falls and were subjected to a formal medico legal autopsy in the Athens Forensic Medical Department from January 1, 1996 to February 8, 2001, was reviewed and a set of trauma outcome variables (template) was constructed.

\section{The template with trauma outcome variables was used for comparisons of the PFx group versus the control group}

Data to construct the template with outcome variables were extracted from the Attica - Trauma Audit and Research Autopsy-Based Registry and included the following: demographics; location of injury; intention for the injury; mechanism of injury classified according to the International Statistical Classification of diseases, injuries and causes of death - 9th revision (ICD-9) [3]; toxicology; distribution of all injuries in the anatomic regions and their severity codes as defined by the Abbreviated Injury Scale - 1990 revision (AIS-90) [4]; potential causes of major haemorrhage other than PFx; postmortem Injury Severity Score (ISS) [5]; posttraumatic survival time; comorbidity data; location where death occurred; surgical procedures performed; complication rates; estimation of deaths directly attributed to PFx; as well as estimation of the proportion of potentially preventable deaths.

\section{Mechanisms of injury}

With respect to mechanisms of injury, only patients with fatal falls were included in the study and were split into simple falls (SF) and non-simple falls (non-SF). SF were defined, according to ICD-9 codes E885, E886, E884.2, as a fall with the victim standing or sitting [6].

\section{Diagnosis and classification of injuries}

The diagnoses of injuries were based on the autopsy examinations but hospital data were also incorporated when they were available. All recorded injuries were retrospectively included in the registry. Consequently injuries were classified according to AIS and ISS by a single coder (NK), and reviewed by the first author.

\section{Causes of major haemorrhage}

In order to identify potential causes of major haemorrhage other than PFx, a list of coded injuries shown in Table 1 was selected from the AIS-90 and their presence or absence in the PFx group were evaluated [2].

\section{Deaths attributed to pelvic fractures}

Deaths attributable to PFx were based on modification of the definition used by Demetriades and colleagues [7] and included patients with: 1) severity of PFx equal to or higher than AIS4; 2) absence of any other injury in any other anatomic region with severity equal to or higher than AIS4; 3) death should have occurred within the first 48 hours after injury in order to be attributable to PFx; and 4) the recorded injuries with an AIS-90 code shown in Table 1 which denote a potential cause of major haemorrhage other than those related to PFx.

\section{Potentially preventable deaths}

Deaths were defined as potentially preventable/salvageable under optimal care when the patients had an ISS equal or less than 74 in the context that the injuries do not necessarily lead to death. Non-preventable/unsalvageable deaths were defined when the ISS was equal to 75 .

\section{Statistical analysis}

Nonparametric statistical tests, i.e. Mann-Whitney or Chi-squared tests as well as logistic regression models were used when appropriate. Multivariate analyses were adjusted for gender, age, intention for injury, and height 
Table 1 Injuries potentially causing major haemorrhage in trauma patients other than the pelvic fractures, as previously used [2]

\begin{tabular}{|c|c|}
\hline Description of Injury & AIS-90 codes \\
\hline Carotid artery & 2.2.02.04.3, 3.2.02..** $.^{* *} .2 .04 .^{* * *}$ \\
\hline Jugular vein & 3.2.06. $.^{* *}, 3.2 .08 .^{* * *}$ \\
\hline Penetrating injuries with blood loss $>20 \%$ by volume & 1.60.06.3, 2.1.60.06.3, 3.1.60.06.3, 5.1.60.06.3, 7.1.60.06.3, 8.1.60.06.3 \\
\hline Skin laceration with blood loss > 20\% by volume & 1.1.06.06.3, 2.1.06.06.3, 3.1.06.06.3, 4.1.06.06.3, 5.1.06.06.3, 7.1.06.06.3, 8.1.06.06.3 \\
\hline Skin avulsion with blood loss >20\% by volume & 1.1.08.06.3, 2.1.08.06.3, 3.1.08.06.3, 4.1.08.06.3, 5.1.08.06.3, 7.1.08.06.3, 8.1.08.06.3 \\
\hline Aorta & $4.2 .02 .^{* * *}, 5.2 .02 .^{* * *} .^{*}$ \\
\hline Innominate vessels & 4.2.04.****, 4.2.06.*** \\
\hline Pulmonary vessels & $4.2 .10 . .^{* *} *, 4.2 .12 .^{* * *}$ \\
\hline Subclavian vessels & $4.2 .14 . .^{* *}, 4.2 .16 .^{* * *}$ \\
\hline Vena cava & 4.2.18.****, 5.2.12.**** \\
\hline Myocardium & 4.4.12..*** $, 4.4 .10 . .^{* *} .{ }^{*}, 4.4 .13 . .^{* * *}$ \\
\hline Celiac artery & $5.2 .04 .^{* * *}$ \\
\hline Named abdominal vessels & 5.2.14. $.^{* *}, 5.2 .16 .^{* * *}$ \\
\hline Liver & 5.4.18.14.3, 5.4.18.24.3 \\
\hline Spleen & $5.4 .42 .^{* * *}$ \\
\hline Kidney & 5.4.16.14.3, 5.4.16.24.3, 5.4.16.40.3 \\
\hline Mesentery with blood loss $>20 \%$ by volume & 5.4 .20 .24 .3 \\
\hline Omentum laceration major with blood loss $>20 \%$ by volume & 5.4.22.24.3 \\
\hline Limb crush & 7.1.30.***, 8.1.30.*** \\
\hline Traumatic amputation (except fingers, toes) & 7.1.10..***, 8.1.10..*.* \\
\hline Axillary vessels major laceration & 7.2.02.08.3, 7.2.04.06.3 \\
\hline Brachial vessels major laceration & 7.2.06.08.3, 7.2.08.06.3 \\
\hline Major lacerations of other named vessels of upper limb & 7.2.10.08.3, 7.2.12.06.3 \\
\hline Femoral vessels & 8.2.02.*** 8.2.04.*** \\
\hline Popliteal vessels & $8.2 .06 . .^{* * *}, 8.2 .08 .^{* * *}$. \\
\hline Major lacerations of other named vessels of lower limb & $8.2 .10 . .^{* * *}, 8.2 .12 . .^{* *}$. \\
\hline
\end{tabular}

*Asterisks that follow the AIS-90 codes indicate that the complete range of injuries was included. AIS-90: Abbreviated Injury Scale - 1990 revision. Severity of injuries ranged from 1 to 6 , with AIS1 being minor, AIS2 moderate, AIS3 serious, AIS4 severe, AIS5 critical, and AIS6 an unsurvivable injury.

of fall. The level of $p<0.05$ was chosen to indicate statistical significance. All statistical tests were performed using Stata statistical software, version 6.0 (Stata Corp, College Station, TX, USA).

\section{Ethics}

The ethics committees of the University General Hospital 'Attikon' and the Forensic Medical Department of Athens approved this study.

\section{Results}

\section{Sample size}

The number of deaths attributable to falls (ICD-9, E50) reported by the National Statistics Service of Greece [8] throughout Greece for the period 1996 to 2000 was 2,102 . The present study included 970 (46\%) fatalities due to falls for approximately the same period of time i.e. January 1, 1996 to February 8, 2001.

\section{Pelvic fracture group, control group and rates}

The dataset consisted of 970 patients who suffered blunt trauma due to falls, of whom 209 (21.5\%) had PFx and constituted the PFx group. The remaining 761 (78.5\%) without PFx constituted the control group.

The PFx group represented 4.2\% of the total 5,007 allcauses trauma fatalities excluding those that were due to drowning and poisoning, who were subjected to formal autopsy during the study period. PFx rates increased from 1996 to 2000 (Pearson chi-squared [4 df] = 15.20, $p=0.004)$.

\section{Risk factors for pelvic fractures}

$\mathrm{n}$ order to identify risk factors for PFx, a multivariate logistic regression model was constructed. PFx was taken as the dependent variable and gender, age, intention for injury, and height of fall as the independent variables. The analysis revealed that all the above factors influenced the probability of subjects suffering a PFx after a fall. Consequently, all of the following analyses were adjusted for gender, age, intention, and height of fall.

\section{Gender}

The PFx group included $125(59.8 \%)$ males and 84 $(40.2 \%)$ females, and the control group 501 (65.8\%) 
males and 260 (34.2\%) females. After adjustment for age, height of fall, and intention, it was shown that males had 28\% lower odds of developing a PFx following a fall compared to females, but this was marginally statistically insignificant $(\mathrm{OR}=0.723,95 \% \mathrm{CI}: 0.521-1.003$, $p=0.052)$.

\section{Age}

The PFx group had a median age of 55 (15-96) years and a mean age $( \pm \mathrm{SD})$ of $54( \pm 20)$ years, while the control group had a median of 66 (range 1-99) years and a mean $( \pm$ SD) of $60.6( \pm 21.5)$ years. The PFx group was statistically significantly younger than the controls (two-sample Wilcoxon rank-sum [Mann-Whitney] test, $p<0.0001)$. The test is a nonparametric one that is suitable for comparison, since the distribution of age was not normal (Shapiro-Wilk W test for normal distribution of variable "age", $p<0.0001$ ).

When age was used as a continuous variable and examined as a risk factor for PFx, the multivariate logistic regression analysis (adjusted for gender, height of fall, and intention) showed that age was a notable predictor. For a one-year difference in age throughout the age range of patients, the odds ratio was equal to 0.988 (95\% CI: 0.981-0.996, $p=0.002$ ). This finding means that older people appear to have a significantly lower probability of suffering a PFx after a fall compared to younger subjects.

\section{Location of injury}

Of the 209 patients of the PFx group, 163 (78\%) were injured in the Greater Athens region, 10 (4.8\%) in the provinces, and $36(17.2 \%)$ at another or unknown location.

Of the 761 patients of the control group, 500 (65.7\%) were injured in the Greater Athens region, 70 (9.2\%) in the provinces, and the remaining 191 (25.1\%) at another or unknown location.

Comparison of the above percentages revealed a substantial difference (Pearson chi-squared [2 df] $=11.29$, $p=0.004$ ) and indicated that a fall occurring in the Greater Athens region had a greater probability of causing a PFx than a fall occurring in the provinces.

\section{Intention for the injury}

Stratification of the intention of the injury revealed that for the PFx group suicidal falls were the most common subset with 114 (54.5\%), followed by unintentional falls with 54 (25.8\%), while those for whom the cause could not be determined was 39 (18.7\%), and falls due to assaults $2(1 \%)$.

The control group comprised 532 (69.9\%) subjects of unintentional falls, 143 (18.8\%) of suicidal falls, 79 (10.4\%) for whom the cause could not be determined and $7(0.9 \%)$ due to assaults. The intention for the injury was associated with the probability of having a PFx (Pearson chi-squared [2 df] $=138.17, p<0.001$ ). In particular, those who had intended to commit suicide had a higher probability of developing a PFx after a fall compared to those who did not have such an intention, (see Additional file 1).

\section{Mechanism of injury: simple falls versus non-simple falls}

The mechanism of injury was split into simple falls and non-simple falls. The commonest mechanism of injury in the PFx group was non-SF in 155 (74.2\%), followed by $\mathrm{SF}$ in $42(20.1 \%)$. The height of fall was unknown in 12 (5.7\%).

The commonest mechanism of injury in the control group was SF in 412 (54.1\%), followed by non-SF in 317 (41.7\%). The height of fall was unknown in 32 (4.2\%). Comparison indicates that the mechanism of injury is associated with the probability of having a PFx (Pearson chi-squared [2 df] $=77.06, p<0.001$ ). In particular, nonSF appear to have a significantly higher probability of resulting in a PFx compared to SF, (see Additional file 2).

\section{Height of fall}

The median height of fall of the non-SF was 13 (3-200) metres for the PFx group and 9 (1-80) metres for the control group. When the height of fall was used as a continuous variable and examined as a risk factor for a PFx, the multivariate logistic regression analysis (adjusted for gender, age, and intention) revealed that the height of fall was a notable predictor, because for a one-metre increment in the height of fall, the odds ratio was equal to 1.012 (95\% CI: $1.006-1.019, p<0.001)$.

\section{Toxicology}

Toxicology screening was performed in 192 of 209 (91.9\%) of the PFx group and in 462 of 761 (60.7\%) of the control group. Alcohol or illegal drugs of any blood concentration were found in $33(17.2 \%)$ of the PFx group and in 89 (19.3\%) of the control group, but there was no significant difference between the groups (Pearson chi-squared [1 df] $=0.385, p=0.54$ ).

\section{AIS-90 anatomic regions and severity codes}

All injuries observed in the 209 patients of the PFx group were classified according to anatomic regions and the AIS-90 severity codes are shown in Table 2. A high severity as well as multiplicity and complexity of injuries were documented.

Analysis of 163 (78\% of the total 209) potentially preventable deaths with an ISS over 16 but less than 75 showed that the anatomic regions which most commonly suffered injuries with a severity of AIS3-5 were the lower extremities in 133 (81.6\%), thorax in 130 (79.7\%), abdominal and 
Table 2 The 209 patients with pelvic fractures and their injuries categorised according to the Abbreviated Injury Scale-90 severity codes and body regions. This classification offers a comprehensive and reproducible overview of the encountered spectrum of severity and the multiplicity of injuries

\begin{tabular}{|c|c|c|c|c|c|c|c|}
\hline \multirow[b]{2}{*}{$\begin{array}{l}\text { AIS-90 } \\
\text { anatomic regions }\end{array}$} & \multirow{2}{*}{$\begin{array}{c}\text { Total } \\
\\
\text { AIS1-6: } \\
2,369 \\
\text { injuries, } \\
\text { in } \\
209 \\
\text { patients. } \\
\text { N, (\%) }\end{array}$} & \multicolumn{4}{|c|}{$\begin{array}{c}\text { ISS } \geq 16 \text { to }<75 \\
163(78 \%) \text { patients } \\
\text { (potentially preventable deaths) }\end{array}$} & \multicolumn{2}{|c|}{$\begin{array}{c}\text { ISS }=75 \\
46(22 \%) \text { patients } \\
\text { (nonpreventable } \\
\text { deaths) }\end{array}$} \\
\hline & & $\begin{array}{c}\text { AIS3: } \\
461 \\
\text { injuries, } \\
\text { in } \\
153 \\
\text { patients, } \\
\mathrm{N},(\%)\end{array}$ & $\begin{array}{c}\text { AIS4: } \\
224 \text { injuries, } \\
\text { in } \\
131 \\
\text { patients. } \\
\mathrm{N},(\%)\end{array}$ & $\begin{array}{c}\text { AIS5: } \\
190 \text { injuries, } \\
\text { in } \\
119 \\
\text { patients. } \\
\text { N, (\%) }\end{array}$ & $\begin{array}{c}\text { AIS } 3+4+5: \\
875 \\
\text { injuries, } \\
\text { in } \\
163 \\
\text { patients. } \\
\mathrm{N},(\%)\end{array}$ & $\begin{array}{c}\text { AIS1-5: } \\
554 \\
\text { injuries, } \\
\text { in } \\
46 \\
\text { patients. } \\
\mathrm{N},(\%)\end{array}$ & $\begin{array}{c}\text { AIS6: } \\
55 \\
\text { injuries, } \\
\text { in } \\
42 \\
\text { patients. } \\
\mathrm{N},(\%)\end{array}$ \\
\hline \multicolumn{8}{|l|}{ 1. Head } \\
\hline Injuries & $328(13.8)$ & $\begin{array}{c}119 \\
(25.8) \\
\end{array}$ & $45(20.1)$ & $\begin{array}{c}6 \\
(3.2) \\
\end{array}$ & $\begin{array}{c}170 \\
(19.4) \\
\end{array}$ & $\begin{array}{c}68 \\
(12.3) \\
\end{array}$ & $\begin{array}{c}17 \\
(30.9)\end{array}$ \\
\hline Patients & $155(74.2)$ & $\begin{array}{c}92 \\
(60.1)\end{array}$ & $30(22.9)$ & $\begin{array}{c}5 \\
(4.2)\end{array}$ & $\begin{array}{c}95 \\
(58.3)\end{array}$ & $\begin{array}{c}29 \\
(63)\end{array}$ & $\begin{array}{c}17 \\
(40.5)\end{array}$ \\
\hline \multicolumn{8}{|l|}{ 2. Face } \\
\hline Injuries & $231(9.7)$ & $\begin{array}{c}2 \\
(0.4)\end{array}$ & $\begin{array}{c}2 \\
(0.9)\end{array}$ & $\begin{array}{c}0 \\
(0)\end{array}$ & $\begin{array}{c}4 \\
(0.5)\end{array}$ & $\begin{array}{c}53 \\
(9.6)\end{array}$ & $\begin{array}{c}0 \\
(0)\end{array}$ \\
\hline Patients & $110(52.6)$ & $\begin{array}{c}2 \\
(1.3)\end{array}$ & $\begin{array}{c}2 \\
(1.5)\end{array}$ & $\begin{array}{c}0 \\
(0)\end{array}$ & $\begin{array}{c}4 \\
(2.4)\end{array}$ & $\begin{array}{c}26 \\
(56.5)\end{array}$ & $\begin{array}{c}0 \\
(0)\end{array}$ \\
\hline \multicolumn{8}{|l|}{ 3. Neck } \\
\hline Injuries & $\begin{array}{c}16 \\
(0.7)\end{array}$ & $\begin{array}{c}0 \\
(0)\end{array}$ & $\begin{array}{c}0 \\
(0)\end{array}$ & $\begin{array}{c}1 \\
(0.5)\end{array}$ & $\begin{array}{c}1 \\
(0.1)\end{array}$ & $\begin{array}{c}2 \\
(0.4)\end{array}$ & $\begin{array}{c}0 \\
(0)\end{array}$ \\
\hline Patients & $\begin{array}{c}14 \\
(6.7)\end{array}$ & $\begin{array}{c}0 \\
(0)\end{array}$ & $\begin{array}{c}0 \\
0 \\
(0)\end{array}$ & $\begin{array}{c}1 \\
(0.8)\end{array}$ & $1(0.6)$ & $\begin{array}{c}2 \\
(4.3)\end{array}$ & $\begin{array}{c}0 \\
(0)\end{array}$ \\
\hline \multicolumn{8}{|l|}{ 4. Thorax } \\
\hline Injuries & $492(20.8)$ & $\begin{array}{l}42 \\
(9.1)\end{array}$ & $96(42.9)$ & $139(73.2)$ & $\begin{array}{c}277 \\
(31.7)\end{array}$ & $\begin{array}{c}106 \\
(19.1)\end{array}$ & $\begin{array}{c}16 \\
(29.1)\end{array}$ \\
\hline Patients & $191(91.4)$ & $\begin{array}{c}39 \\
(25.5)\end{array}$ & $84(64.1)$ & $93(78.1)$ & $\begin{array}{l}130 \\
(79.7)\end{array}$ & $\begin{array}{c}42 \\
(91.3)\end{array}$ & $\begin{array}{c}16 \\
(38.1)\end{array}$ \\
\hline \multicolumn{8}{|c|}{ 5. Abdominal \& pelvic contents } \\
\hline Injuries & $313(13.2)$ & $\begin{array}{c}81 \\
(17.6)\end{array}$ & $66(29.5)$ & $\begin{array}{c}3 \\
(1.6)\end{array}$ & $\begin{array}{l}150 \\
(17.1)\end{array}$ & $\begin{array}{c}70 \\
(12.6)\end{array}$ & $\begin{array}{c}8 \\
(14.5)\end{array}$ \\
\hline Patients & $153(73.2)$ & $\begin{array}{c}71 \\
(46.4)\end{array}$ & $63(48.1)$ & $\begin{array}{c}3 \\
(2.5)\end{array}$ & $\begin{array}{c}99 \\
(60.7)\end{array}$ & $\begin{array}{c}35 \\
(76.1)\end{array}$ & $\begin{array}{c}7 \\
(16.7)\end{array}$ \\
\hline \multicolumn{8}{|l|}{ 6. Spine } \\
\hline Injuries & $103(4.3)$ & $\begin{array}{c}15 \\
(3.2)\end{array}$ & $2(0.9)$ & $\begin{array}{l}12 \\
(6.3)\end{array}$ & $\begin{array}{c}29 \\
(3.3)\end{array}$ & $\begin{array}{c}25 \\
(4.5)\end{array}$ & $\begin{array}{c}14 \\
(25.4)\end{array}$ \\
\hline Patients & $68(32.5)$ & $\begin{array}{l}13 \\
(8.5)\end{array}$ & $2(1.5)$ & $\begin{array}{c}11 \\
(9.2)\end{array}$ & $\begin{array}{c}26 \\
(15.9)\end{array}$ & $\begin{array}{c}15 \\
(32.6)\end{array}$ & $\begin{array}{c}11 \\
(26.2)\end{array}$ \\
\hline \multicolumn{8}{|c|}{ 7. Upper extremities } \\
\hline Injuries & $286(12.1)$ & $\begin{array}{c}43 \\
(9.3)\end{array}$ & $\begin{array}{c}0 \\
(0)\end{array}$ & $\begin{array}{c}0 \\
(0)\end{array}$ & $\begin{array}{c}43 \\
(4.9)\end{array}$ & $\begin{array}{c}78 \\
(14.1) \\
\end{array}$ & $\begin{array}{c}0 \\
(0)\end{array}$ \\
\hline Patients & $136(65.1)$ & $\begin{array}{c}20 \\
(13.1)\end{array}$ & $\begin{array}{c}0 \\
(0)\end{array}$ & $\begin{array}{c}0 \\
(0)\end{array}$ & $\begin{array}{c}20 \\
(12.3)\end{array}$ & $\begin{array}{c}34 \\
(73.9)\end{array}$ & $\begin{array}{c}0 \\
0 \\
(0)\end{array}$ \\
\hline \multicolumn{8}{|c|}{$\begin{array}{l}\text { 8. Lower extremities } \\
\text { (all injuries) }\end{array}$} \\
\hline Injuries & $570(24.1)$ & $\begin{array}{c}159 \\
(34.5)\end{array}$ & $\begin{array}{c}13 \\
(5.8)\end{array}$ & $28(14.7)$ & $\begin{array}{c}200 \\
(22.9)\end{array}$ & $\begin{array}{c}145 \\
(26.2)\end{array}$ & $\begin{array}{c}0 \\
(0)\end{array}$ \\
\hline Patients & $209(100)$ & $\begin{array}{c}105 \\
(68.6)\end{array}$ & $\begin{array}{c}13 \\
(9.9)\end{array}$ & $28(23.5)$ & $\begin{array}{c}133 \\
(81.6)\end{array}$ & $\begin{array}{c}46 \\
(100)\end{array}$ & $\begin{array}{c}0 \\
0 \\
(0)\end{array}$ \\
\hline
\end{tabular}


Table 2 The 209 patients with pelvic fractures and their injuries categorised according to the Abbreviated Injury Scale-90 severity codes and body regions. This classification offers a comprehensive and reproducible overview of the encountered spectrum of severity and the multiplicity of injuries (Continued)

8. Lower extremities
(Pelvic fracture codes only) 8.5.26.**.*, 8.5.28.**.*,
8.5.30.**.*)

\begin{tabular}{|c|c|c|c|c|c|c|c|}
\hline Injuries & $\begin{array}{c}214 \\
(9)\end{array}$ & $\begin{array}{c}79 \\
(17.1)\end{array}$ & $\begin{array}{c}13 \\
(5.8)\end{array}$ & $28(14.7)$ & $\begin{array}{c}120 \\
(13.7)\end{array}$ & $\begin{array}{c}47 \\
(8.5)\end{array}$ & $\begin{array}{c}0 \\
(0)\end{array}$ \\
\hline Patients & $209(100)$ & $\begin{array}{c}77 \\
(50.3)\end{array}$ & $\begin{array}{c}13 \\
(9.9)\end{array}$ & $28(23.5)$ & $\begin{array}{c}118 \\
(72.4)\end{array}$ & $\begin{array}{c}46 \\
(100)\end{array}$ & $\begin{array}{l}0 \\
(0)\end{array}$ \\
\hline \multicolumn{8}{|c|}{ 9. External } \\
\hline Injuries & $\begin{array}{c}30 \\
(1.3) \\
\end{array}$ & $\begin{array}{c}0 \\
(0) \\
\end{array}$ & $\begin{array}{c}0 \\
(0)\end{array}$ & $\begin{array}{c}1 \\
(0.5) \\
\end{array}$ & $\begin{array}{c}1 \\
(0.1) \\
\end{array}$ & $\begin{array}{c}7 \\
(1.3) \\
\end{array}$ & $\begin{array}{c}0 \\
(0) \\
\end{array}$ \\
\hline Patients & $\begin{array}{c}17 \\
(8.1)\end{array}$ & $\begin{array}{c}0 \\
(0)\end{array}$ & $\begin{array}{c}0 \\
(0)\end{array}$ & $\begin{array}{c}1 \\
(0.8)\end{array}$ & $\begin{array}{c}1 \\
(0.6)\end{array}$ & $\begin{array}{c}3 \\
(6.5)\end{array}$ & $\begin{array}{c}0 \\
(0)\end{array}$ \\
\hline
\end{tabular}

*The asterisks that follow the AIS-90 codes indicate that the complete range of injuries was included; AIS-90: Abbreviated Injury Scale, 1990 revision; ISS: Injury Severity Score.

pelvic contents in 99 (60.7\%), head in 95 (58.3\%), and spine in $26(15.9 \%)$.

\section{Injury Severity Score}

There were no patients with an ISS less than 16 in the PFx group and this allows its definition as a severely injured group.

The median ISS of the PFx group was 50 (17-75) and the mean ISS 51.0 ( $\mathrm{SD} \pm 16.3$ ), while the median ISS of the control group was 26 (1-75) and the mean ISS 30.6 (SD \pm 18.9). The median ISS for the PFx group was significantly higher than the ISS for the control group (two-sample Wilcoxon rank-sum [Mann-Whitney] test, $p<0.0001$ ).

\section{ISS and age}

The PFx group and the control group were further categorised by ISS and age higher or lower than 55 years, as shown in Table 3 because age has a prognostic value. The PFx group included higher proportions in the ISS groups of 50-74 and 75, than the control group. Within the PFx group the ISS groups of 50-74 and 75 were more commonly found in the age group less than 55 years, while the less severe ISS groups were more common in the age group 55 and older.

\section{Preventable deaths}

Based on the definition of the study, 163 (78\% of the total 209) deaths in the PFx group had an ISS less than 75 and were categorized as potentially preventable, while 46 (22\%) had an ISS of 75 and were considered not preventable.

\section{Associated injuries}

The complete range of recorded injuries was classified according to the AIS-90 anatomic regions and the AIS-90 severity codes, having first excluded the non-preventable deaths, i.e. 46 (22\% of the total 209) from the PFx group and 66 (8.7\% of the total 761$)$ from the control group with an ISS equal to 75 .

Hence, comparison of associated injuries was limited to a subset of 163 (78\%) patients from the PFx group, versus a subset of 695 (91.3\%) from the control group, all of whom had an ISS less than 75 and were classified as potentially preventable deaths. Univariate logistic regression analyses were performed and followed by multivariate logistic regression analysis to adjust for age, gender, intention, and height of fall. Multiplicity and severity of associated injuries were significantly more common in most anatomic regions in the PFx group than in the control group. The full results are shown in Table 4 and Figure 1.

Table 3 Categorisation of all 209 patients of the PFx group and all 761 patients of the control group by age and Injury Severity Score (ISS). All patients of the PFx group suffered severe trauma with an ISS equal to 17 or higher

\begin{tabular}{lllllllll}
\hline & \multicolumn{3}{l}{ Age $<5$ years } & \multicolumn{4}{l}{ Age $\geq \mathbf{5 5}$ years } \\
\hline & \multicolumn{3}{l}{ PFx group } & \multicolumn{1}{l}{ Control group } & \multicolumn{2}{l}{ PFx group } & \multicolumn{2}{l}{ Control group } \\
\cline { 2 - 9 } ISS-groups & $\mathbf{N}$ & $\%$ & $\mathbf{N}$ & $\%$ & $\mathbf{N}$ & $\%$ & $\mathbf{N}$ & $\%$ \\
\hline $1-8^{*}$ & 0 & 0 & 3 & 1.1 & 0 & 0 & 21 & 4.3 \\
\hline $9-15$ & 0 & 0 & 21 & 7.9 & 0 & 0 & 91 & 18.4 \\
\hline $16-24$ & 3 & 3 & 40 & 15 & 4 & 3.7 & 103 & 20.9 \\
\hline $25-40$ & 20 & 19.8 & 100 & 37.5 & 27 & 25 & 188 & 38.1 \\
\hline $41-49$ & 14 & 13.9 & 35 & 13.1 & 22 & 20.4 & 30 & 6.1 \\
\hline $50-74$ & 40 & 39.6 & 29 & 10.9 & 33 & 30.6 & 34 & 6.9 \\
\hline 75 & 24 & 23.8 & 39 & 14.6 & 22 & 20.4 & 27 & 5.5 \\
\hline Totals & 101 & 100 & 267 & 100 & 108 & 100 & 494 & 100 \\
\hline
\end{tabular}

*The 24 victims of the control group with ISS 1-8 suffered a major complication such as acute myocardial infarction, pulmonary embolism and multiple organ failure. 
Table 4 Comparison of associated injuries between the subsets of patients of the PFx group and the control group, who had an ISS of less than $\mathbf{7 5}$ and were classified as potentially preventable deaths. Associated severe injuries were significantly more common in the PFx group than in the control group

\begin{tabular}{|c|c|c|c|c|c|c|c|}
\hline \multirow[t]{2}{*}{$\begin{array}{l}\text { Injuries: Anatomic Region, } \\
\text { (AIS-90 codes) }\end{array}$} & \multicolumn{2}{|c|}{$\begin{array}{l}\text { PFx } \\
\text { group }\end{array}$} & \multicolumn{2}{|c|}{$\begin{array}{l}\text { Control } \\
\text { group }\end{array}$} & \multicolumn{2}{|c|}{$\begin{array}{l}\text { After adjustment for age, } \\
\text { gender, intention, and } \\
\text { height of fall }\end{array}$} & \multirow[t]{2}{*}{$p$-value } \\
\hline & $\mathrm{n}$ & $\%$ & $\mathrm{n}$ & $\%$ & ORt & $95 \% \mathrm{Cl}$ & \\
\hline Total number of patients analysed & 163 & 100 & 695 & 100 & & & \\
\hline Head, $\left(1 . .^{* * * * * *}\right),($ AIS1-5) & 112 & 68.7 & 575 & 82.7 & 0.42 & $0.28-0.63$ & $<0.001$ \\
\hline Brain, (1.4.******), (AIS3-5) & 92 & 56.4 & 535 & 77.0 & 0.33 & $0.23-0.49$ & $<0.001$ \\
\hline Skull, $\left(1.5 .^{* * * * *}{ }^{* *}\right),($ AIS2-4) & 47 & 28.8 & 393 & 56.6 & 0.27 & $0.18-0.40$ & $<0.001$ \\
\hline Thorax, $\left(4 . .^{* * * * * * *}\right),($ AIS1-5) & 145 & 89.0 & 278 & 40.0 & 10.54 & $6.25-17.79$ & $<0.001$ \\
\hline Thoracic wall, $\left(4.5\right.$. . $\left.^{* * * * *}\right),($ AIS2-5) & 137 & 84.1 & 232 & 33.4 & 9.36 & $5.94-14.76$ & $<0.001$ \\
\hline Thoracic viscera, $\left(4.4 .^{* * * * *}\right.$.*), (AIS2-5) & 99 & 60.7 & 129 & 18.6 & 5.90 & $4.01-8.66$ & $<0.001$ \\
\hline Thoracic vessels $\left(4.2^{* * * * * *}\right),($ AIS2-5) & 28 & 17.2 & 36 & 5.2 & 3.47 & $2.00-6.02$ & $<0.001$ \\
\hline Abdominal, $\left(5 . * * * * * *{ }^{* *}\right),($ AIS1-5) & 117 & 71.8 & 145 & 20.9 & 8.36 & $5.54-12.59$ & $<0.001$ \\
\hline Abdominal/pelvic viscera, $\left(5.4 .^{* * * * *} .^{*}\right)$, (AIS1-5) & 112 & 68.7 & 123 & 17.7 & 9.07 & $6.03-13.66$ & $<0.001$ \\
\hline Liver, (5.4.18.***), (AIS2-5) & 76 & 46.6 & 78 & 11.2 & 5.83 & $3.86-8.79$ & $<0.001$ \\
\hline Spleen, (5.4.42.***), (AIS2-5) & 57 & 35.0 & 70 & 10.1 & 4.21 & $2.74-6.47$ & $<0.001$ \\
\hline Gastrointestinal tract, $\left(5.4 .44 .{ }^{* * *} ., 5.4 .10 . .^{* * *}, 5.4 .14 .{ }^{* * *} ., 5.4 .08 . .^{* *}{ }^{*}, 5.4 .36 . .^{* * *}\right.$ ), (AIS2-5) & 3 & 1.8 & 8 & 1.2 & 1.16 & $0.29-4.56$ & 0.834 \\
\hline Abdominal vessels, $\left(5.2 .^{* * * * * *}\right)$, (AlS2-5) & 0 & 0.0 & 1 & 0.1 & \multicolumn{2}{|c|}{ Cannot be estimated } & \\
\hline Diaphragm, $\left(4.4 .06 .^{* *} .{ }^{*}\right),($ AIS2-3) & 5 & 3.1 & 6 & 0.9 & 2.57 & $0.75-8.83$ & 0.133 \\
\hline Kidney, (5.4.16.***), (AIS2-5) & 38 & 23.3 & 31 & 4.5 & 5.17 & $3.04-8.82$ & $<0.001$ \\
\hline Bladder, $\left(5.4 .06 .^{* * *}{ }^{*}\right),($ AIS2-4) & 0 & 0.0 & 1 & 0.1 & \multicolumn{2}{|c|}{ Cannot be estimated } & \\
\hline 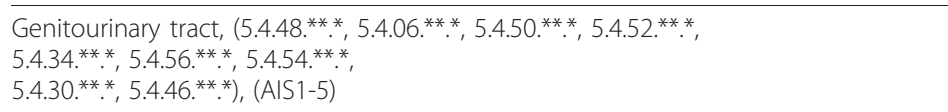 & 5 & 3.1 & 2 & 0.3 & 11.64 & $2.08-65.0$ & 0.005 \\
\hline Perineum, (5.4.32.***), (AIS1-3) & 2 & 1.2 & 1 & 0.1 & 7.77 & $0.60-100.0$ & 0.116 \\
\hline Spine, $\left(6^{* * * * * * *}\right),($ AlS2-5) & 45 & 27.6 & 98 & 14.1 & 2.40 & $1.57-3.65$ & $<0.001$ \\
\hline Cervical spine, (6.3.02.****, 6.4.02.****, 6.5.02.***), (AIS2-5) & 30 & 18.4 & 77 & 11.1 & 2.11 & $1.30-3.43$ & 0.003 \\
\hline Thoracic spine, $\left(6.3 .04 .{ }^{* * *} ., 6.4 .04 .{ }^{* * *} .{ }^{*}, 6.5 .04 .{ }^{* *} .{ }^{*}\right),($ AIS2-5) & 18 & 11.0 & 25 & 3.6 & 2.90 & $1.50-5.62$ & 0.002 \\
\hline Lumbar spine, (6.3.06..***, 6.4.06.**.*, 6.5.06.***), (AIS2-5) & 3 & 1.8 & 5 & 0.7 & 2.79 & $0.62-12.55$ & 0.182 \\
\hline Upper extremities, $\left(7 . *^{* * * * * *}\right),($ AIS1-3) & 102 & 62.6 & 279 & 40.1 & 2.07 & $1.44-2.99$ & $<0.001$ \\
\hline Upper limb skeletal trauma, $(7.5 . * * * * *)$, (AIS1-3) & 59 & 36.2 & 105 & 15.1 & 2.77 & $1.87-4.11$ & $<0.001$ \\
\hline Humerus, $\left(7.5 .26 .^{* * *}\right),($ AlS2-3) & 29 & 17.8 & 37 & 5.3 & 3.37 & $1.96-5.81$ & $<0.001$ \\
\hline Forearm, (7.5.28.***, 7.5.32.***), (AIS2-3) & 29 & 17.8 & 23 & 3.3 & 5.79 & $3.17-10.57$ & $<0.001$ \\
\hline Lower extremities, $\left(8 . *^{* * * * * * *}\right),($ AIS1-5) & 114 & 69.9 & 271 & 39.0 & 3.15 & $2.16-4.60$ & $<0.001$ \\
\hline $\begin{array}{l}\text { Lower limb skeletal trauma, }\left(8.5 .^{* * * * * *} \text { besides pelvis: } 8.5 .26 . .^{* * *} \text {, }\right. \\
8.5 .28 . .^{* * *}, 8.5 .30 . .^{* * *} \text { ), (AIS1-3) }\end{array}$ & 162 & 99.4 & 120 & 17.3 & 762.6 & $105.3-5525$ & $<0.001$ \\
\hline Femur, (8.5.18. $\left.{ }^{* *} .{ }^{*}\right),($ AIS2-3) & 45 & 27.6 & 74 & 10.7 & 3.20 & $2.06-4.97$ & $<0.001$ \\
\hline Tibia, $\left(8.5 .34 . .^{* *} .{ }^{*}, 8.5 .16 . .^{* *} .{ }^{*}\right),($ AIS1-3) & 38 & 23.3 & 38 & 5.5 & 4.44 & $2.68-7.36$ & $<0.001$ \\
\hline Acetabulum-hip, (8.5.06.***, 8.5.26.00.2), (AIS1-2) & 4 & 2.5 & 3 & 0.4 & 5.63 & $1.15-27.65$ & 0.033 \\
\hline 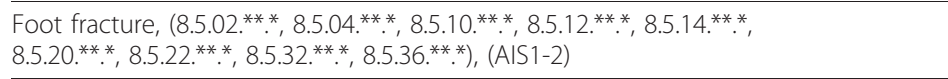 & 8 & 4.9 & 8 & 1.2 & 3.48 & $1.24-9.79$ & 0.018 \\
\hline Calcaneus fracture, (8.5.14.00.2), (AIS2) & 3 & 1.8 & 1 & 0.1 & 11.80 & $1.14-121.9$ & 0.038 \\
\hline
\end{tabular}

*The asterisks that follow the AIS-90 codes indicate that the complete range of injuries was included. Injuries are ranked on a scale of 1 to 6 , with 1 being minor 2 moderate, 3 serious, 4 severe, 5 critical, and 6 not compatible with life injury.

§PFx group versus control group.

AIS-90, Abbreviated Injury Scale - 1990 revision; OR, odds ratio; PFx, pelvic fractures. 


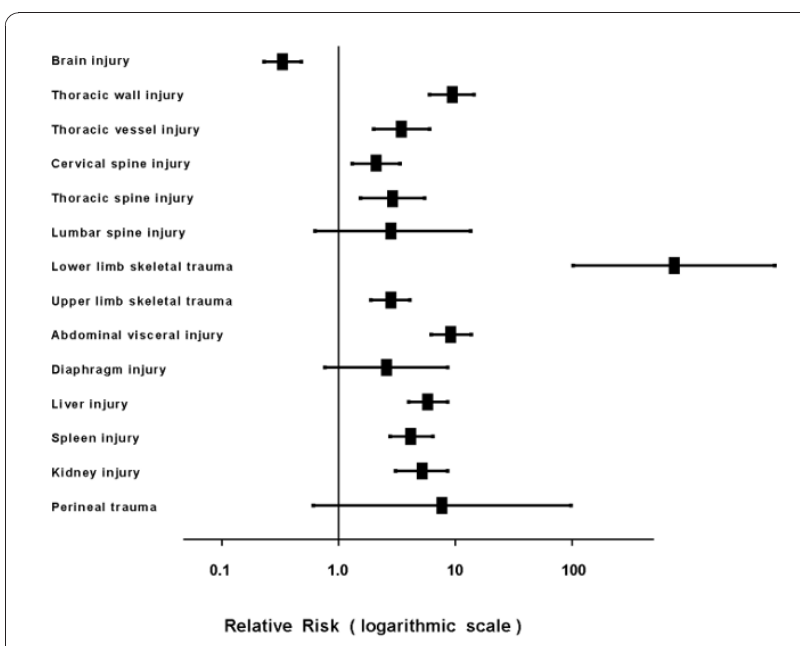

Figure 1 Forest plot of injuries associated with pelvic fractures Odds ratios are adjusted for gender, age, intention, and height of fall, and are displayed on a logarithmic scale. The vertical line represents no association with pelvic fracture (odds ratio of 1.0). When the line for an injury does not cross the vertical line, there is a statistically significant association between the particular injury and pelvic fracture.

There were recorded data allowing classification of PFx as open or closed for 189 (90.4\%) of the 209 patients of the PFx group. There were 3 (1.6\% of 189) patients with open PFx and 186 (98.4\% of 189) with closed PFx. The open PFx subset had a median ISS of 55 (41-75) and the closed PFx subset an ISS of 50 (17$75)$. In addition, the median post-traumatic survival time for the open PFx subset was 23 minutes (0-70 minutes) and for the closed PFx subset 30 minutes (0-1,180 hours and 45 minutes).

\section{Haemorrhage}

Assessment of the subset of the PFx-group that consisted of 163 potentially preventable deaths (ISS less than 75), with respect to the presence of haemorrhage, revealed that $126(60.3 \%)$ of the total 209 subjects with PFx, or $73.3 \%$ of the total 163 potentially preventable deaths of the PFx group, had at least one AIS-90 code listed in Table 1 which denoted a potential cause of major haemorrhage other than the PFx.

\section{Transfer time}

Of the 209 patients in the PFx group, 116 (55.5\%) were initially admitted to a hospital in the Greater Athens region and $6(2.9 \%)$ to a hospital in the provinces; the remaining $87(41.6 \%)$ were either not admitted to any hospital or their status was unknown.

Of the 761 patients of the control group, 500 (65.7\%) were initially admitted to a hospital in the Greater Athens region and $70(9.2 \%)$ to a hospital in the provinces; the remaining 191 (25.1\%) were either not admitted to any hospital or their status was unknown.

The time elapsing from injury to arrival in the emergency department was estimated for the PFx group, having first excluded the 132 (63.2\%) victims who were found dead at the scene and the $37(17.7 \%)$ for whom data were missing. For the remaining 40 (19.1\% of the total 209) patients, the median transfer time was 22.5 minutes (10-90 minutes).

The transfer time for the control group was estimated, having first excluded the 256 (33.6\%) subjects who were found dead at the scene, $383(50.3 \%)$ for whom the transfer time was missing and $2(0.3 \%)$ subjects who were classified as secondary deaths. For the remaining $120(15.8 \%)$ patients the median transfer time was 30 minutes (range 5 minutes to 30 hours).

There were no significant differences with respect to transfer time between the PFx and control groups.

\section{Comorbidities}

The rates of reported, but non-stratified with respect to severity, comorbid conditions of the PFx group were compared to those of the control group after adjustment for gender, age, intention, and height of fall. There were no statistically significant differences between the two groups with respect to chronic obstructive airways disease, ischaemic heart disease, congestive heart failure, hypertension, diabetes mellitus, obesity, cirrhosis, or alcohol/drug dependency. However, an approximately $300 \%$ higher odds of having a psychiatric history was found in the PFx group compared to the control group (OR: 4.18, 95\% CI: 2.52-6.95, $p<0.001$ ).

\section{Surgical operations performed}

Of the 209 patients in the PFx group, a subset of only $25(11.9 \%)$ left the emergency department alive to undergo additional treatment. Nearly half of the patients needed a surgical operation and abdominal operations were significantly more common in the PFx than in the control group (see Additional file 3).

\section{Complications}

Pneumonia was reported in two patients and pulmonary embolism in another two of the 25 who were admitted to a hospital.

\section{Deaths directly attributed to pelvic fractures}

Applying all four predefined criteria limited the proportion of deaths directly attributed to pelvic fractures to six $(2.9 \%)$, Table 5 .

\section{Post-traumatic survival time}

The exact time of injury or time of death was missing for 70 patients in the PFx group and for 221 patients 
Table 5 Deaths directly attributed to pelvic fractures

\begin{tabular}{lll}
\hline PFx group. & N & $\%$ \\
\hline Patients with PFx AIS $\leq 3$ in severity who were excluded. & 209 & 100 \\
\hline Remaining patients with PFx AIS4 and AIS5 in severity. & 55.7 & 26.3 \\
\hline $\begin{array}{l}\text { Remaining patients without any, other than PFx injury of } \\
\text { AlS } \geq 4 \text { in } \\
\text { severity, in any other AIS anatomic region. }\end{array}$ & 6 & 2.9 \\
\hline Post-injury survival time $\leq 48$ h. & 6 & 2.9 \\
\hline $\begin{array}{l}\text { Patients without any injuries listed in Table 1, which denote } \\
\text { a potential cause of major haemorrhage other than those } \\
\text { related to PFx. }\end{array}$ & 6 & 2.9 \\
\hline PFx: & & \\
\hline
\end{tabular}

PFx: pelvic fracture; AIS: Abbreviated Injury Scale (the scale of injury severity ranges from 1 to 6 , with 1 being minor, 2 moderate, 3 serious, 4 severe, 5 critical, and 6 an unsurvivable injury).

in the control group. Comparison of the post-traumatic survival time of the remaining 139 (66.5\%) patients of the PFx group, versus the post-traumatic survival time of the $540(71.0 \%)$ patients of the control group revealed that the median post-traumatic survival time for the PFx group was 30 minutes and for the control group 20 hours and 15 minutes. The difference between the groups was highly significant (two-sample Wilcoxon rank-sum [Mann-Whitney] test, $p<0.001)$. The distribution of deaths over the corresponding post-traumatic survival time for the PFx-group is shown in Figure 2.

\section{Correlation of post-traumatic survival time with the ISS- groups}

A subset of 139 (66.5\%) patients of the PFx group for whom the posttraumatic survival time was known was classified with respect to severity in the following ISSgroups, 16-24, 25-40, 41-49, 50-74, and 75, and the percentages of deaths over the following post-traumatic survival time intervals less than $10 \mathrm{~min}, 10-60 \mathrm{~min}, 60-$

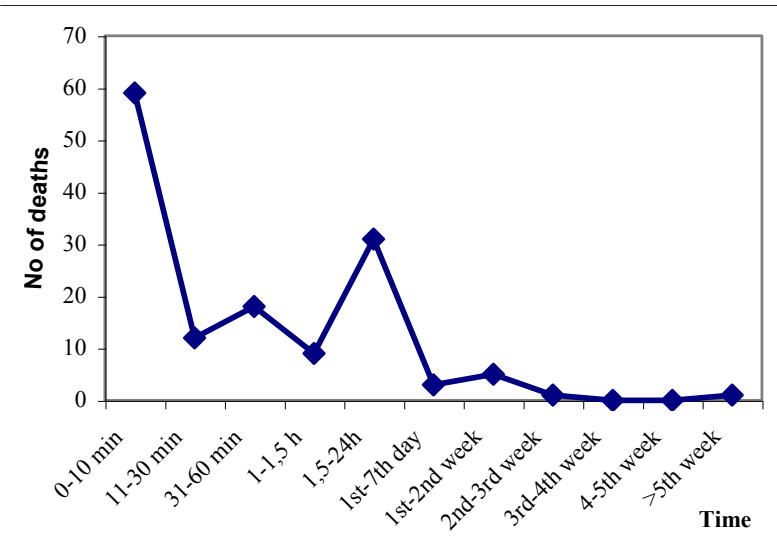

Figure 2 Distribution of 139 of the 209 (66.5\%) patients of the PFx group over the corresponding post-traumatic survival time substantiates the time limits during the early management.
120 min, 2-6 hours, 6-24 hours, 1-3 days, 3-7 days, 1-3 weeks, 3-6 weeks, more than 6 weeks, were compared after adjustment for age, gender, height of fall, and intention for the injury. Ordered logistic regression analysis was used and revealed that for a one-group increment in the range of ISS groups, the probability of survival was reduced by $57 \%$ (OR: $0.43,95 \% \mathrm{CI}, 0.32$ $0.58, p<0.0001$ ), Figure 3.

\section{Location of deaths}

With respect to the location of death, a significantly higher proportion of patients, i.e. 147 (70.3\%) of the PFx group were found dead at the scene or were dead on arrival, versus the 325 (42.7\%) patients of the control group (Pearson chi-squared $[6 \mathrm{df}]=140.31$, $p<0.001$ ).

From the PFx group, a subset of $184(88 \%)$ who died at the scene, were dead on arrival, or died in the emergency department had a median ISS of 50 (19-75), while the remaining $25(12 \%)$ patients who left the emergency department alive for additional treatment had a median ISS of 38 (17-75). The difference was statistically significant (two-sample Wilcoxon rank-sum (Mann-Whitney) test, $\mathrm{p}<0.001$ ). The relevant data are shown in Table 6.

\section{Discussion}

\section{Main results}

Comparison of the PFx group with the control group documented that PFx is a paradigm of injury that selected a population from the total fatal falls that shared common characteristics. The relevance of the trauma outcome variables (template) used to compare the two groups and their contribution to audit is further discussed herein.

\section{Mortality due to PFx}

Falls are the second most common cause of traumarelated deaths, after MVC in Greece and in North America [8,9]. The management of patients with PFx has been widely discussed elsewhere [10-13]. In two large-scale studies $[7,14]$, the reported in hospital mortality of patients with PFx was $13.5 \%$ and $17.7 \%$ respectively. However, PFx are associated with higher mortality rates when pre hospital trauma fatalities are included in the studies.

\section{The need for systematic audit of trauma care}

The need for an evidence-based transformation of the system to an optimal [15] trauma care system in Greece, has been recognised and substantiated by other studies [16-21]. Data such as those produced by the present method can contribute to essential components of a nationally-based registry $[22,23]$. 


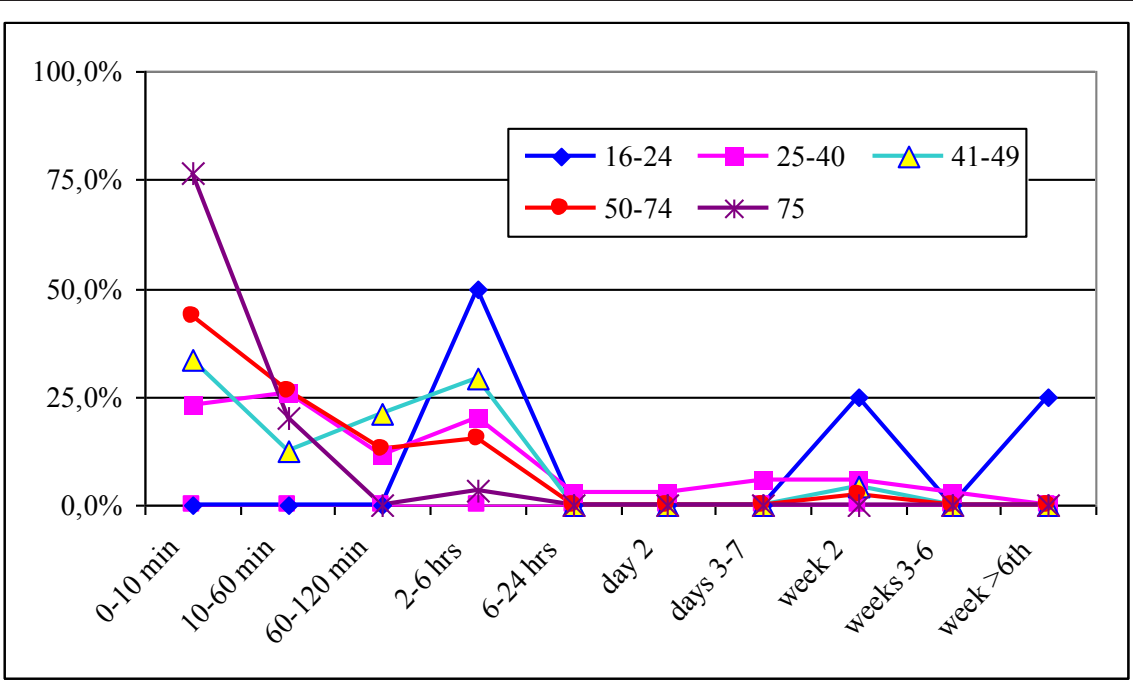

Figure 3 Correlation of post-traumatic survival time with the ISS groups. The post-traumatic survival time was known for 139 of the 209 (66.5\%) patients of the PFx group. There were no subjects with an ISS of less than 17. The percentage of deaths in the ISS groups 16-24, 25-40, 41-49, 50-74, and 75 , over the corresponding post-traumatic survival time confirm that the most severely injured patients die earlier than the less severely injured.

\section{Sample size}

The present study is representative as it included approximately $46 \%(n=970)$ of the 2,102 deaths due to falls (ICD-9, E50), which occurred throughout Greece for the study period 1996 to 2000 .

\section{Rates of PFx}

Selection of subjects with PFx reduced the sample size to $21.5 \%$ (209) of the total 970 subjects who suffered a fatal fall. Hence, a reduced number of autopsies are required to repeat the audit. Importantly, similar proportions of patients with PFx (17.8\% [24], $23 \%$ [25], 23\% [26], (25.4\%) [2] have been reported in trauma autopsy and clinical studies and indicate the availability of subjects on which to base auditing procedures.

\section{Risk factors for PFx}

In the present study, multivariate analysis revealed that gender, age, intention for the accident, and height of fall increased the probability of suffering a PFx after a fall. Hence, the PFx group shared common risk factors. Materials structured by the described method allowed the identification of common risk factors for PFx which are important for developing primary prevention programmes [27].

\section{Gender}

The present study has shown that men had 28\% lower odds of developing a PFx following a fall compared to females. Hence, the PFx used as a paradigm of injury selected a lower proportion of men than women from the total sample. Data on the predictive value of gender on the trauma outcome are still controversial $[28,29]$.

Table 6 Location of death of the 209 patients in the PFx group

\begin{tabular}{|c|c|c|c|c|c|c|}
\hline \multirow[b]{2}{*}{ Location of death } & \multicolumn{3}{|c|}{ PFx group } & \multicolumn{3}{|c|}{ Control group } \\
\hline & $\mathbf{n}$ & $\%$ & Median ISS (range) & $\mathbf{n}$ & $\%$ & Median ISS (range) \\
\hline Found dead & 132 & 63.2 & $57(24-75)$ & 256 & 33.6 & $41(5-75)$ \\
\hline Dead on arrival & 15 & 7.1 & 38 (19-75) & 69 & 9.1 & $19(1-75)$ \\
\hline Emergency department death & 37 & 17.7 & $43(22-75)$ & 53 & 7 & $29(3-75)$ \\
\hline Operating room death & 10 & 4.8 & $43(22-75)$ & 10 & 1.3 & $34.5(10-54)$ \\
\hline Intensive care unit death & 11 & 5.3 & $34(17-50)$ & 126 & 16.6 & $26(9-75)$ \\
\hline Ward death & 4 & 1.9 & $32(17-50)$ & 226 & 29.7 & $18(1-59)$ \\
\hline *Secondary death & 0 & 0 & 0 & 21 & 2.8 & $9(4-54)$ \\
\hline Total & 209 & 100 & $50(17-75)$ & 761 & 100 & $26(1-75)$ \\
\hline
\end{tabular}

*Secondary deaths were defined as those that occurred after the discharge of the patient from the hospital. ISS: Injury Severity Score; PFx: pelvic fracture. 
Age

The present study revealed that age was a notable predictor because each one-year increment of age was associated with a decrease in the odds of suffering a PFx after a fall by $1.2 \%$. This finding is skewed from that of a previous study [2] and reaffirms that different agegroups are prone to suffering trauma via different mechanisms.

Moreover, age is a well-known predictive factor following trauma [5] and is a vital parameter for audit. It has been reported that increased mortality starts at the age of 40 years [30], but other authors have reported that the cut-off of age-dependent mortality at the age of 56 years and this increase is independent of the injury severity [31]. Evidence-based guidelines with respect to management of elderly trauma patients have been proposed elsewhere [32].

\section{Location of injury, rural trauma and the need for regionalisation of care}

In the present study, the observed significantly higher risk for a PFx after a fall in the Greater Athens region than in the provinces reflects differences with respect to professional and other activities of the patients, between the capital and the provinces.

Rural trauma is associated with a higher mortality rate than urban trauma [33]. Mapping the location of injury should indicate the environmental factors predisposing to trauma. Key issues for effective upgrading of the care of trauma patients in rural regions are comprehensively discussed elsewhere [34].

\section{Intention for the injury}

In the present study, people who had the intention of committing suicide had a higher probability of developing a PFx after a fall compared to those who did not have such an intention. The reported suicide rate for Greece in 1997 was 2.8 per 100,000 citizens [35]. Suicide is a huge but preventable public health problem [36]. The data of the present study indicate that prevention measures should be re-addressed in Greece.

Unintentional falls at workplaces, homes, and those related to childhood and sporting activities are important concerns [37].

In this study, the height of fall was a notable predictor, because for a one-metre increment in the height of fall the rates of PFx increased $(p<0.001)$. SF in the elderly, are not so simple because the relative risk of in-hospital death is 15 times higher in the elderly compared with patients younger than 65 years [38]. Safety measures are fields for preventive actions $[27,39,40]$.

\section{Mechanism of injury classified by the ICD-9}

The mechanism of injury provides an insight into anticipated patterns of injury. Data classified according to ICD-9, as in the present study, allow global comparisons. In addition, derivatives of ICD-9 have been shown to outperform both ISS and TRISS as predictors of trauma survival, hospital charges and length of hospital stay [41].

\section{Toxicology}

The presence of alcohol in $17.2 \%$ of the PFx group and in $19.3 \%$ of the control group was the most common pre-injury co-morbid condition. The emerging concept of preventive interventions by trauma centres with respect to alcohol and illicit drugs should be addressed in this country also [42].

\section{Severity assessment: AIS-90 anatomic regions and severity codes}

Severity of injury is the most important determinant of survival following injury. In the present study, analysis of 163 (78\% of the total 209) potentially preventable deaths (ISS less than 75) outlined the distribution and relative frequencies of the injuries in the anatomic regions as well as their AIS-90 severity codes. AIS-90 severity codes and anatomic regions were indispensable in classifying and comparing the groups of patients with PFx to those without.

\section{ISS}

In the present study, the PFx used as a paradigm selected more severely injured patients than the control group and this has been substantiated as all subjects of the PFx group had an ISS equal to or higher than 17, the median ISS of the PFx group was 50 (17$75)$, while the median ISS of the control group was 26 (1-75) and the difference between the groups was statistically significant. Distribution of deaths in the PFx group in relation to the ISS showed that patients with a higher ISS died during earlier stages of medical care than those with a lower ISS. An ISS higher than 25 has been reported to be a risk factor associated with mortality of patients with PFx [7].

The postmortem-based ISS may differ from clinically estimated antemortem ISS [43] and earlier studies on preventable trauma deaths that were based on autopsy reports were strongly criticised as being inconsistent and subjective $[44,45]$. However, in the present study the autopsy reports were used to extract the description of the injuries that were consequently classified by the AIS-90 anatomic descriptions, severity codes, and ISS. 
Omitting the pre-hospital trauma deaths from analyses would affect the spectrum of severity descriptions as well as the epidemiological data [22] and potentially the trauma care policies.

\section{Associated injuries}

The present study has reaffirmed that the associated injuries coded according to AIS-90 in the potentially preventable (ISS less than 75) subset were a significantly more common feature in the PFx group than in the control group (Table 4 and Figure 1).

Falls from heights result in visceral, vascular, and skeletal injuries [10,24,26].

Large energy absorption is required to produce a PFx and the energy dissipation caused many associated injuries. The present study indicated that when selecting the PFx paradigm a reproducible population should be selected, thus allowing data comparison.

\section{Deaths directly attributed to PFx}

Based on the definitions of the study, 2.9\% $(n=6)$ of the deaths were attributed to PFx per se, while the remainder had multiple other associated injuries, which led to death. The reported overall in hospital mortality of subjects with PFx is $13.5 \%$, but only $0.8 \%$ of the deaths were attributed to PFx [7].

\section{Control of haemorrhage is a primary issue for audit}

AIS-90-coded injuries, shown in Table 1 that denoted a potential cause of major haemorrhage other than the PFx, were encountered in $126(60.3 \%)$ of the 209 subjects with PFx in the present study. Haemodynamic stability is a predictor of mortality [46], as unstable patients with PFx have mortality rates of $40-50 \%$ [47-49]. Hence, the timeliness of interventions performed on the patients is inevitably a subject for audit. A protocol [50] and guidelines [32] for the initial management have been recommended elsewhere.

\section{Comorbidity}

In the present study, age was an indication of the functional reserve capacities of the patients $[51,52]$. Comorbidity is a known trauma outcome predictor [30,53-55] and a key issue that is needed to compare groups of patients when auditing trauma care $[56,57]$.

A number of non-stratified diagnoses were evaluated but their role has not been elucidated in the present study. For patients who arrive alive at hospital the physical status can be classified by the American Society of Anesthesiologists (ASA) score [58,59], the co-morbidity by the Charlson co-morbidity index [60,61] and the APACHI II pre-injury chronic pathology set of definitions [55,62]. However, for a more accurate autopsybased audit there is a need to develop autopsy-based grading of the severity of these common co-morbid conditions.

\section{Triage}

Physiology derangement, anatomic injury diagnosis, mechanism of injury, pre-existing comorbid conditions [57] and ASA [59] are commonly used to triage trauma patients. Trauma score alone does not seem adequate for pre-hospital triage of patients with PFx [63]. In the present study, the significantly higher ISS values as well as the shorter post-traumatic survival time of the PFx group in comparison to controls, substantiate the rational practice which gives priority in transferring subjects with suspicion of PFx to high-level trauma centres [11].

\section{Transfer time and the Emergency Medical Care Service}

Despite the relatively short median transferring times, some patients were transferred to the first available hospital and others to more organised units capable of managing major trauma, a fact that raises the issue of regionalisation of care in this country $[64,65]$. The Greek national EMCS, named EKAB [66], is the major means of trauma patients' transportation. However, data to audit its effectiveness are not regularly published $[67,68]$.

\section{Performed surgery}

The patterns of injuries that occur in falls were previously reported $[10,26]$ and are comprehensively analysed in the present study, Table 2 and 4.

The pathophysiology [69] as well as the management of patients are discussed elsewhere [10,70,71]. In the present study abdominal surgery was significantly more commonly performed on the PFx group than on the control group. The proportion of patients who required a timely surgical intervention in relation to those who actually received this management is of paramount importance to assess standards of care, but the data do not allow any conclusions.

\section{Complications}

The rates and stratification of severity of the most common in hospital complications are essential outcome measures. Avoiding errors in management, assuring effective treatment of multiple organ failure, sepsis, and pulmonary embolism would decrease trauma mortality [72]. To allow wide comparisons clear definitions of complications should be followed [73].

\section{Correlation of post-traumatic survival time to ISS}

The median post-traumatic survival time for the PFx group was 30 minutes, while for the control group it was 20 hours and 15 minutes. The difference between the groups was highly significant and substantiates the 
time limits during the initial management of patients with PFx.

The correlation of the post-traumatic survival rates with the corresponding times to death revealed that as the severity (assessed by the ISS) increases, the survival rate of subjects of the PFx group decreases, Figure 3. Correlation of the ISS groups with the corresponding post-traumatic survival time should be a basic indicator for comparisons and audit.

\section{Location of death in relation to ISS group}

A higher proportion of patients in the PFx group died sooner than those in the control group and did not have the opportunity for in hospital medical care. This was substantiated in the present study, as a significantly higher proportion of patients, i.e. $70.4 \%(n=147)$ of the PFx group were found dead at the scene or were dead on arrival at hospital, versus $42.7 \%(\mathrm{n}=325)$ of the patients of the control group, a fact that reflects the higher severity of injury in the PFx group.

Previously reported rates of trauma deaths in the prehospital phase were $60.3 \%$ [74], and for trauma occurring in rural areas $70.5 \%$ [33]. It is of primary importance for auditing trauma care to know the proportion of potentially preventable deaths (ISS less than 75) among the patients who died without receiving specialised in-hospital care. The location of death in relation to ISS group should be a major index of the standards of trauma care.

\section{Non-preventable deaths as an argument for primary prevention programmes}

In the present study 46 (22\% of the total 209) patients with PFx were classified as non-preventable deaths (ISS equal to 75 ). This subset of deaths can only be avoided by primary injury prevention programmes. More than half of all trauma deaths are potentially preventable with pre-injury behavioural changes. Injury prevention is critical for reducing deaths in modern trauma systems [72] and the present study produced evidence for the establishment of prevention programmes as discussed earlier. The ratio of potentially preventable (ISS less than 75) to non-preventable deaths (ISS equal to 75) was 3.5:1 (163:46). These data should be used for future comparisons.

\section{Consistency of the presented data with standards of reporting trauma data}

With respect to the standards for uniform reporting of data following major trauma, the present study showed that a substantial number of variables previously recommended [75] can be incorporated in an autopsy-based audit study.

\section{What makes patients with PFx a paradigm?}

Skewing of the PFx population to the control group with respect to epidemiological data was shown. However, the most striking differences between the PFx group and the control group were the different risk factors and mechanisms of injury, the multiplicity of the associated injuries, the severity of the associated injuries, the high rates of injuries that caused major haemorrhage and the short post-traumatic survival time, which were significantly more commonly encountered in the PFx group. The described population with PFx shared common characteristics, and can be identified by the described methodology, allowing their definition as a paradigm of population. The described method produced a comprehensive overview of current trauma care.

\section{Study limitations}

The main limitations of this study are its retrospective design and the lack of survivors for comparisons. The lack of systematic pre-mortem physiology data precluded the application of functional scores such as the revised trauma score [76] and the TRISS methodology for audit [77]. Standardised autopsy reports as well as autopsy based grading of comorbidity and refinement of the definition of deaths attributable to PFx should increase the validity of the method.

\section{Is the described method of autopsy data analysis reproducible and sustainable?}

In the present study, the method of autopsy data analysis produced similar results to those of a previous study [2] from the same institutions. Reproduction by other authors remains to be seen. The applicability of this template was confirmed and should ensure a selection of comparable trauma populations. However, adjusted models of autopsy reports for trauma victims [78] as well as a systematic critical analysis of autopsy findings [79] is required to compare groups of subjects more accurately.

\section{Conclusions}

The trauma population with PFx has characteristics that allow its definition as a paradigm of injury. Selection of the paradigm reduces the sample of an autopsy-based audit that renders systematic autopsy-based audit easier to apply. The structured template included a set of trauma outcome variables which substantially contributed to the audit of functional, infrastructural, management and prevention issues of the trauma care system and produced evidence for future comparisons. Further formulation of the method is a challenge for autopsy based trauma research. 


\section{Additional material}

\section{Additional file 1: Comparison of age and ISS between PFx and} control groups. The median age and the median Injury Severity Score (ISS), of the patients who were injured by the two most common categories of intention for the accident.

Additional file 2: Comparison of age and ISS between simple falls and non-simple falls. Median age and Injury Severity Score (ISS) of the victims of simple falls (SF) and non-simple falls (non-SF).

Additional file 3: Performed Surgical Operations. Performed Surgical Operations.

\section{Abbreviations and acronyms}

AIS-90: Abbreviated Injury Scale - 1990 revision; EMCS: Emergency medical care service; PFx: Pelvic fracture; ISS: Injury Severity Score; ICD-9: International Statistical Classification of diseases, injuries and causes of death - 9th revision; MVC: Motor vehicle collisions; Non-SF: Non-simple falls; OR: Odds ratio; SF: Simple fall

\section{Acknowledgements}

The National \& Kapodistrian University of Athens has partially supported this research with the programme 'Kapodistrias' 70/7/8146.

An abstract of this manuscript was presented in the Congress of the British Orthopaedic Association 2008.

\section{Author details}

'National \& Kapodistrian University of Athens, Attikon University General Hospital, Fourth Surgery Department, 1 Rimini Street, 124 62, Athens, Greece. ${ }^{2}$ Department of Epidemiological Surveillance \& Intervention, Center for Diseases Control \& Prevention, Athens, Greece. ${ }^{3}$ The Athens Forensic Medical Department, Ministry of Justice, 10 Anapaphseos Street, 116 36, Athens, Greece.

\section{Authors' contributions}

INP, NKK: Study conception and design. INP, NKK, CL: Acquisition of data. INP, SB, GK, KP, SC, OK: Analysis and interpretation. INP: Drafting, writing of manuscript. All authors have read and approved the final version of the manuscript.

\section{Competing interests}

The authors declare that they have no competing interests.

Received: 30 January 2010 Accepted: 8 January 2011

Published: 8 January 2011

\section{References}

1. Siegel JH, Dalal SA, Burgess AR, Young JW: Pattern of organ injuries in pelvic fracture: impact force implications for survival and death in motor vehicle injuries. Accid Anal Prev 1990, 22:457-466.

2. Papadopoulos IN, Kanakaris N, Bonovas S, Triantafillidis A, Garnavos C Voros D, Leukidis C: Auditing 655 fatalities with pelvic fractures by autopsy as a basis to evaluate trauma care. J Am Coll Surg 2006, 203:30-43.

3. World Health Organisation (WHO): Manual of the International Classification of Diseases, injuries and causes of death. 9th Revision. Athens 1980.

4. Association for the Advancement of Automotive Medicine: The Abbreviated Injury Scale. 1990 rev. Des Plaines, IL 1990.

5. Baker SP, O'Neill B, Haddon W, Long WB: The injury severity score: a method for describing patients with multiple injuries and evaluating emergency care. J Trauma 1974, 14:187-196.

6. Centers for Disease Control and Prevention: International Classification of Diseases, Ninth Revision, Clinical Modification (ICD-9-CM) 2007.

7. Demetriades D, Karaiskakis M, Toutouzas K, Alo K, Velmahos G, Chan L: Pelvic fractures: epidemiology and predictors of associated abdominal injuries and outcomes. J Am Coll Surg 2002, 195:1-10.

8. National Center for Health Statistics (NCHS). [http://www.statistics.gr].
9. American College of Surgeons Committee on Trauma. [http://www.ntdb org].

10. Buckman RF, Buckman PD: Vertical deceleration trauma. Principles of management. Surg Clin North Am 1991, 71:331-344.

11. Lee C, Porter K: The prehospital management of pelvic fractures. Emerg Med J 2007, 24:130-133.

12. Papakostidis C, Kanakaris NK, Kontakis G, Giannoudis PV: Pelvic ring disruptions: treatment modalities and analysis of outcomes. Int Orthop 2009, 33:329-338.

13. Giannoudis PV, Pape HC: Damage control orthopaedics in unstable pelvic ring injuries. Injury 2004, 35:671-677.

14. Pohlemann T, Bosch U, Gansslen A, Tscherne H: The Hannover experience in management of pelvic fractures. Clin Orthop Relat Res 1994, 69-80.

15. American College of Surgeons Committee on Trauma: Resources for optimal care of the injured patient 2006.

16. Papadopoulos IN: Report of preventable prehospital trauma deaths in a Greek health care region: importance of editorial comments. J Trauma 2007, 62:1316

17. Papadopoulos IN, Bukis D, Karalas E, Katsaragakis S, Stergiopoulos S, Peros G, Androulakis G: Preventable prehospital trauma deaths in a Hellenic urban health region: an audit of prehospital trauma care. $J$ Trauma 1996, 41:864-869.

18. Papadopoulos IN, Kanakaris N, Triantafillidis A, Stefanakos J, Kainourgios A, Leukidis C: Autopsy findings from 111 deaths in the 1999 Athens earthquake as a basis for auditing the emergency response. $\mathrm{Br} J$ Surg 2004, 91:1633-1640.

19. Papadopoulos IN, Kanakaris N, Triantafillidis A, Stefanakos J, Voros D, Leukidis C: Autopsy findings of Post-Traumatic Pneumonia from 2583 deaths due to Motor Vehicle Accidents. J Surg Infections, 17th Annual meeting of Surgical Infection Society-EUR; Cork, Ireland. Surgical Infections 2004, 132-133.

20. Papadopoulos IN, Papaefthymiou M, Roumeliotis L, Panagopoulos VG, Stefanidou A, Kostaki A: Status and perspectives of hospital mortality in a public urban Hellenic hospital, based on a five-year review. BMC Public Health 2008, 8:28.

21. Christodoulou C, Papadopoulos IN, Douzenis A, Kanakaris N, Leukidis C Gournellis R, Vlachos K, Papadopoulos FC, Lykouras L: Seasonality of violent suicides in the athens greater area. Suicide Life Threat Behav 2009, 39:321-331.

22. Harviel JD, Landsman I, Greenberg A, Copes WS, Flanagan ME, Champion HR: The effect of autopsy on injury severity and survival probability calculations. J Trauma 1989, 29:766-772, discussion 772-763.

23. Scheib BT, Thompson ME, Kerns TJ: Federal influences on the development of trauma registers. J Trauma 1989, 29:835-841.

24. Richter D, Hahn MP, Ostermann PA, Ekkernkamp A, Muhr G: Vertical deceleration injuries: a comparative study of the injury patterns of 101 patients after accidental and intentional high falls. Injury 1996, 27:655-659.

25. Adams JE, Davis GG, Heidepriem RW, Alonso JE, Alexander CB: Analysis of the incidence of pelvic trauma in fatal automobile accidents. Am J Forensic Med Pathol 2002, 23:132-136.

26. Scalea T, Goldstein A, Phillips T, Sclafani SJ, Panetta T, McAuley J, Shaftan G: An analysis of 161 falls from a height: the 'jumper syndrome'. J Trauma 1986, 26:706-712.

27. World Health Organisation (WHO) Regional Office for Europe. [http:// www.euro.who.int/document/E82552.pdf].

28. Gannon CJ, Napolitano LM, Pasquale M, Tracy JK, McCarter RJ: A statewide population-based study of gender differences in trauma: validation of a prior single-institution study. J Am Coll Surg 2002, 195:11-18.

29. Rappold JF, Coimbra R, Hoyt DB, Potenza BM, Fortlage D, Holbrook T, Minard G: Female gender does not protect blunt trauma patients from complications and mortality. J Trauma 2002, 53:436-441, discussion 441

30. Morris JA, MacKenzie EJ, Damiano AM, Bass SM: Mortality in trauma patients: the interaction between host factors and severity. J Trauma 1990, 30:1476-1482.

31. Kuhne CA, Ruchholtz S, Kaiser GM, Nast-Kolb D: Mortality in severely injured elderly trauma patients-when does age become a risk factor? World J Surg 2005, 29:1476-1482.

32. Eastern Association for the Surgery of Trauma (EAST). [http://www.east. org/tpg/pelvis.pdf]. 
33. Gonzalez RP, Cummings G, Mulekar M, Rodning CB: Increased mortality in rural vehicular trauma: identifying contributing factors through data linkage. J Trauma 2006, 61:404-409.

34. Rogers FB, Shackford SR, Osler TM, Vane DW, Davis JH: Rural trauma: the challenge for the next decade. J Trauma 1999, 47:802-821.

35. Chishti P, Stone DH, Corcoran P, Williamson E, Petridou E: Suicide mortality in the European Union. Eur J Public Health 2003, 13:108-114.

36. World Health Organization (WHO). [http://www.who.int/mediacentre/ news/releases/2004/en/

37. Centers of Disease Control and Preventions: Fatal occupational injuriesUnited States, 1980-1997. MMWR Morb Mortal Wkly Rep 2001, 50:317-320.

38. Bergeron E, Clement J, Lavoie A, Ratte S, Bamvita JM, Aumont F, Clas D: A simple fall in the elderly: not so simple. J Trauma 2006, 60:268-273.

39. American Geriatrics Society, British Geriatrics Society, and American Academy of Orthopaedic Surgeons Panel on Falls Prevention: Guideline for the prevention of falls in older persons. J Am Geriatr Soc 2001, 49:664-672.

40. Feder G, Cryer C, Donovan S, Carter Y: Guidelines for the prevention of falls in people over 65. The Guidelines' Development Group. BMJ 2000, 321:1007-1011.

41. Rutledge R, Osler T, Emery S, Kromhout-Schiro S: The end of the Injury Severity Score (ISS) and the Trauma and Injury Severity Score (TRISS) ICISS, an International Classification of Diseases, ninth revision-based prediction tool, outperforms both ISS and TRISS as predictors of trauma patient survival, hospital charges, and hospital length of stay. J Trauma 1998, 44:41-49.

42. Dunn CW, Donovan DM, Gentilello LM: Practical guidelines for performing alcohol interventions in trauma centers. J Trauma 1997, 42:299-304.

43. Streat SJ, Civil ID: Injury scaling at autopsy: the comparison with premortem clinical data. Accid Anal Prev 1990, 22:241-252.

44. Wilson DS, McElligott J, Fielding LP: Identification of preventable trauma deaths: confounded inquiries? J Trauma 1992, 32:45-51.

45. Trunkey DD: Invited commentary: panel reviews of trauma mortality. J Trauma 1999, 47:S44-45.

46. Starr AJ, Griffin DR, Reinert CM, Frawley WH, Walker J, Whitlock SN, Borer DS, Rao AV, Jones AL: Pelvic ring disruptions: prediction of associated injuries, transfusion requirement, pelvic arteriography, complications, and mortality. J Orthop Trauma 2002, 16:553-561.

47. Agnew SG: Hemodynamically unstable pelvic fractures. Orthop Clin North Am 1994, 25:715-721.

48. Moreno C, Moore EE, Rosenberger A, Cleveland HC: Hemorrhage associated with major pelvic fracture: a multispecialty challenge. $J$ Trauma 1986, 26:987-994.

49. Gansslen A, Giannoudis P, Pape HC: Hemorrhage in pelvic fracture: who needs angiography? Curr Opin Crit Care 2003, 9:515-523.

50. Coppola PT, Coppola M: Emergency department evaluation and treatment of pelvic fractures. Emerg Med Clin North Am 2000, 18:1-27, v.

51. McGwin G Jr, MacLennan PA, Fife JB, Davis GG, Rue LW: Preexisting conditions and mortality in older trauma patients. J Trauma 2004, 56:1291-1296.

52. Perdue PW, Watts DD, Kaufmann CR, Trask AL: Differences in mortality between elderly and younger adult trauma patients: geriatric status increases risk of delayed death. J Trauma 1998, 45:805-810.

53. MacKenzie EJ, Morris JA, Edelstein SL: Effect of pre-existing disease on length of hospital stay in trauma patients. J Trauma 1989, 29:757-764, discussion 764-755.

54. Milzman DP, Boulanger BR, Rodriguez A, Soderstrom CA, Mitchell KA, Magnant CM: Pre-existing disease in trauma patients: a predictor of fate independent of age and injury severity score. J Trauma 1992, 32:236-243, discussion 243-234

55. Sacco WJ, Copes WS, Bain LW, MacKenzie EJ, Frey CF, Hoyt DB, Weigelt JA, Champion HR: Effect of preinjury illness on trauma patient survival outcome. J Trauma 1993, 35:538-542, discussion 542-533.

56. Fleisher LA: Risk indices: what is their value to the clinician and patient? Anesthesiology 2001, 94:191-193.

57. Morris JA, MacKenzie EJ, Edelstein SL: The effect of preexisting conditions on mortality in trauma patients. JAMA 1990, 263:1942-1946.

58. American Society of Anesthesiologists: ASA Physical Status Classification System. [http://www.asahq.org/clinical/physicalstatus.htm].

59. Skaga NO, Eken T, Sovik S, Jones JM, Steen PA: Pre-injury ASA physical status classification is an independent predictor of mortality after trauma. J Trauma 2007, 63:972-978.
60. Camilloni L, Farchi S, Giorgi Rossi P, Chini F, Borgia P: Mortality in elderly injured patients: the role of comorbidities. Int J Inj Contr Saf Promot 2008, 15:25-31.

61. Charlson ME, Pompei P, Ales KL, MacKenzie CR: A new method of classifying prognostic comorbidity in longitudinal studies: development and validation. J Chronic Dis 1987, 40:373-383.

62. McMahon DJ, Schwab CW, Kauder D: Comorbidity and the elderly trauma patient. World J Surg 1996, 20:1113-1119, discussion 1119-1120.

63. Fox MA, Mangiante EC, Fabian TC, Voeller GR, Kudsk KA: Pelvic fractures: an analysis of factors affecting prehospital triage and patient outcome. South Med J 1990, 83:785-788.

64. Grossman DC, Hart LG, Rivara FP, Maier RV, Rosenblatt R: From roadside to bedside: the regionalization of trauma care in a remote rural county. $J$ Trauma 1995, 38:14-21.

65. Sampalis JS, Denis R, Frechette P, Brown R, Fleiszer D, Mulder D: Direct transport to tertiary trauma centers versus transfer from lower level facilities: impact on mortality and morbidity among patients with major trauma. J Trauma 1997, 43:288-295, discussion 295-286.

66. National Emergency Medical Care Service of Greece. [http://www.ekab. gr].

67. National Association of Emergency Medical Technicians in Cooperation with the Committee on Trauma: Pre Hospital Trauma Life Support Mosby, USA 1999.

68. Carney CJ: Prehospital care-a UK perspective. Br Med Bull 1999, 55:757-766.

69. Warner $\mathrm{KG}$, Demling $\mathrm{RH}$ : The pathophysiology of free-fall injury. Ann Emerg Med 1986, 15:1088-1093.

70. Durkin A, Sagi HC, Durham R, Flint L: Contemporary management of pelvic fractures. Am J Surg 2006, 192:211-223.

71. Scalea TM, Burgess AR: Pelvic fractures. New York 2004.

72. Stewart RM, Myers JG, Dent DL, Ermis P, Gray GA, Villarreal R, Blow O, Woods B, McFarland M, Garavaglia J, et al: Seven hundred fifty-three consecutive deaths in a level I trauma center: the argument for injury prevention. J Trauma 2003, 54:66-70, discussion 70-61.

73. Kardooni S, Haut ER, Chang DC, Pierce CA, Efron DT, Haider AH, Pronovost PJ, Cornwell EE: Hazards of benchmarking complications with the National Trauma Data Bank: numerators in search of denominators. J Trauma 2008, 64:273-277, discussion 277-279.

74. Potenza BM, Hoyt DB, Coimbra R, Fortlage D, Holbrook T, HollingsworthFridlund P: The epidemiology of serious and fatal injury in San Diego County over an 11-year period. J Trauma 2004, 56:68-75.

75. Dick WF, Baskett PJ: Recommendations for uniform reporting of data following major trauma-the Utstein style. A report of a working party of the International Trauma Anaesthesia and Critical Care Society (ITACCS). Resuscitation 1999, 42:81-100.

76. Boyd CR, Tolson MA, Copes WS: Evaluating trauma care: the TRISS method. Trauma Score and the Injury Severity Score. J Trauma 1987, 27:370-378.

77. Champion HR, Copes WS, Sacco WJ, Lawnick MM, Keast SL, Bain LW, Flanagan ME, Frey CF: The Major Trauma Outcome Study: establishing national norms for trauma care. J Trauma 1990, 30:1356-1365.

78. Report of the Joint Working Party of the Royal College of Pathologists the Royal College of Physicians of London and the Royal College of Surgeons of England: The Autopsy and audit 1991.

79. Hanzlick RL: The autopsy lexicon: suggested headings for the autopsy report. Arch Pathol Lab Med 2000, 124:594-603.

doi:10.1186/1752-2897-5-2

Cite this article as: Papadopoulos et al: Patients with pelvic fractures due to falls: A paradigm that contributed to autopsy-based audit of trauma in Greece. Journal of Trauma Management \& Outcomes 2011 5:2. 